Vietnam Journal of Mechanics, VAST, Vol. 27, No. 4 (2005), pp. 193-203

\title{
ON THE HIGH RESOLUTION REGIONAL WEATHER FORECAST MODEL (HRM) AND FORECASTING TROPICAL CYCLONE MOTION OVER THE SOUTH CHINA SEA
}

\author{
Le Duc ${ }^{1}$, Le Cong Thanh ${ }^{2}$, Kieu Thi Xin ${ }^{1}$ \\ ${ }^{1}$ Hanoi National University \\ ${ }^{2}$ National Hydro-meteorological Service of Vietnam
}

\begin{abstract}
Chan (1995) [2] has found that, only $70 \%$ in 60 cases of the tropical cyclone (TC) movement test (TMT-90) developed from steering flows. The 30\% remain of cases have to be explained by nonbarotropic processes. We are of the opinion that all weak, slow-moving and unexpected changing TCs over the South China Sea are in this $30 \%$ set. The nonlinear interaction between barotropic and nonbarotropic processes has affected on motion and structure of such TCs. In this paper, we use the high resolution weather forecast model (HRM), which is able to simulate meso-scale phenomena in limited regions, to predict motion of TCs in the South China Sea in 2002-2004, including two typical weak, slow-moving and unexpected changing TCs Mekhala and Nepartak. We have chosen two forecast domains with different areas and resolutions. The results show that with the smaller domain, appropriate buffer and higher resolution HRM can predict better motion of TCs operating in the South China Sea.
\end{abstract}

\section{INTRODUCTION}

In recent years, the theory about tropical cyclone (TC) motion focus on the ideas which assume that TC-motion is caused by barotropic processes on the base of the conservation of the absolute vorticity with two main mechanisms: the advective adjustment by environment flows of the relative vorticity related to TCs (steering flows) and the advective process including the nonlinear impact between steering flows and the gradient of planet vorticity and the circulations of vorticities. Chang (1995) [3] mentioned that those impacts are generated during the evolution of flows with different wave numbers. Advective process resulting from each wave number will generate distribution of vorticity tendency, combined later with the tendency developed from steering flows, which forms the direction of TC (the direction of steering flows). Chan (1995) [2] has found this mechanism taking only $70 \%$ in 60 cases of the TC movement test (TMT-90). The $30 \%$ remain of cases have to be explained by nonbarotropic processes.

Many current studies using numerical models indicated the role of nonbarotropic processes such as the wind shear, the vertical structure of eddy and of the diabatic heating which are responsible for the motion of TCs. The aim of those kinds of studies is to build a theory of the impact of nonbarotropic processes on motions in the atmosphere including TCs motion beside steering flows.

In this paper we concentrate on improving the high resolution regional model (HRM) to predict the motion of the TCs coming into the South China sea with focusing on those which are weak, slow-moving and often change direction unexpectedly such as the two 
typhoons Mekhala (0220) of 2002 and Nepartak (0320) of 2003. This kind of typhoons, after Chan (1995) [2], is only in $30 \%$ of all TCs but they often cause heavy rainfall leading to flooding, economic and social losses.

In the next part we present the verification results of prediction by the improved version of a horizontal resolution of $14 \mathrm{~km}$ and 31 vertical levels (VNUHRM/V14-31) in comparison with the results of the origin version (HRM/V28-20) and of some numerical operational models of the other countries.

\section{THE HIGH RESOLUTION REGIONAL MODEL (HRM)}

HRM is an operational numerical regional weather prediction model of high resolution from the German Weather Service and has been provided to the National Independent Research Project 2000-2001 funded by Ministry of Science and Technology of Viet Nam. Since October 2002 the HRM is used as the first operational model at the Vietnamese National Hydro-Meteorological Service. The details of this model can be seen in Kieu (2002) [10].

\subsection{On the HRM}

HRM is a hydrostatical numerical model for $\alpha$ - and $\beta$ - scale phenomena on limited regions, producing the detailed prediction of near-surface weather parameters and well simulating clouds and rainfall. Hence, meteorological fields of HRM can be used for environmental problems such as polluted air modeling or sea state simulation. This model is also a sensitive research tool. The HRM is built on a rotated latitude-longitude grid or a regular grid with the resolution from $0.25^{0}$ to $0.05^{0}$ ( $28 \mathrm{~km}$ to $6 \mathrm{~km}$, respectively), using a hybrid vertical coordinate. The vertical atmosphere of HRM is from the surface characterized by $p_{s}(x, y, t)$ to the upper bound at $25 \mathrm{mb}$ and can be divided from 20 to 35 levels. The prognostic variables $u, v, T, q_{v}, q_{c}, q_{i}$ and the diagnostic variables such as the vertical velocity in the pressure coordinate $\omega$ are defined in full levels, while the geopotential height $\phi$, the vertical velocity in the hybrid coordinate and the diffusion fluxes are defined in half levels.

\subsection{Fundamental equations of HRM}

The prognostic equations of HRM are derived from the primitive equations in the hybrid coordinate. There are 7 equations for 7 prognostic variable such as [10]:

The surface pressure $p_{s}$ :

$$
\frac{\partial p_{s}}{\partial t}=-\frac{1}{a \cos \varphi} \int_{0}^{1}\left\{\frac{\partial}{\partial \lambda}\left(u \frac{\partial p}{\partial \eta}\right)+\frac{\partial}{\partial \varphi}\left(v \cos \varphi \frac{\partial p}{\partial \eta}\right)\right\} d \eta-\mu_{l b}\left(p_{s}-p_{s l b}\right) .
$$

The horizontal winds $u, v$ :

$$
\begin{aligned}
& \frac{\partial u}{\partial t}-\frac{1}{\cos \varphi} Q \frac{\partial p}{\partial \eta} v \cos \varphi+\frac{1}{a \cos \varphi} \frac{\partial}{\partial \lambda}(\Phi+K)+\frac{R T_{v}}{a \cos \varphi} \frac{\partial}{\partial \lambda}[\ln (p)]+\eta^{*} \frac{\partial u}{\partial \eta}= \\
& =F_{H}^{u}-g\left(\frac{\partial p}{\partial \eta}\right)^{-1} \frac{\partial \tau_{\lambda}}{\partial \eta}+\left(\frac{\partial u}{\partial t}\right)_{s}-\mu_{l b}\left(u-u_{l b}\right),
\end{aligned}
$$




$$
\begin{aligned}
& \frac{\partial v}{\partial t}+Q \frac{\partial p}{\partial \eta} u+\frac{1}{a} \frac{\partial}{\partial \varphi}(\Phi+K)+\frac{R T_{v}}{a} \frac{\partial}{\partial \varphi}[\ln (p)]+\eta^{*} \frac{\partial v}{\partial \eta}= \\
& F_{H}^{v}-g\left(\frac{\partial p}{\partial \eta}\right)^{-1} \frac{\partial \tau_{\varphi}}{\partial \eta}+\left(\frac{\partial v}{\partial t}\right)_{s}-\mu_{l b}\left(v-v_{l b}\right) .
\end{aligned}
$$

The temperature $T$ :

$$
\begin{aligned}
& \frac{\partial T}{\partial t}+\frac{1}{a \cos \varphi}\left[u \frac{\partial T}{\partial \lambda}+v \cos \varphi \frac{\partial T}{\partial \varphi}\right]+\underset{T}{\stackrel{*}{\partial} \frac{\partial T}{\partial \eta}}= \\
& =\frac{R}{c_{p}} T_{v}\left(\frac{\omega}{p}\right)+F_{H}^{T}-g\left(\frac{\partial p}{\partial \eta}\right)^{-1} \frac{\partial \eta_{T}}{\partial \eta}+\left(\frac{\partial T}{\partial t}\right)_{s}+\frac{L_{c}}{c_{p}} c_{v c}-\mu_{l b}\left(T-T_{l b}\right) .
\end{aligned}
$$

The specific humidity $q_{v}$ :

$$
\begin{aligned}
& \frac{\partial q_{v}}{\partial t}+\frac{1}{a \cos \varphi}\left[u \frac{\partial q_{v}}{\partial \lambda}+v \cos \varphi \frac{\partial q_{v}}{\partial \varphi}\right]+\eta^{*} \frac{\partial q_{v}}{\partial \eta}= \\
& F_{H}^{q_{V}}-g\left(\frac{\partial p}{\partial \eta}\right)^{-1} \frac{\partial \eta_{q v}}{\partial \eta}+\left(\frac{\partial q_{v}}{\partial t}\right)_{s}-c_{v c}-\mu_{l b}\left(q_{v}-q_{v l b}\right) .
\end{aligned}
$$

The cloud humidity $q_{c}$ :

$$
\begin{aligned}
& \frac{\partial q_{c}}{\partial t}+\frac{1}{a \cos \varphi}\left[u \frac{\partial q_{c v}}{\partial \lambda}+v \cos \varphi \frac{\partial q_{c}}{\partial \varphi}\right]+\eta^{*} \frac{\partial q_{c}}{\partial \eta}= \\
& F_{H}^{q_{C}}-g\left(\frac{\partial p}{\partial \eta}\right)^{-1} \frac{\partial \eta_{q_{c}}}{\partial \eta}+\left(\frac{\partial q_{c}}{\partial t}\right)_{s}-c_{v c}-\mu_{l b}\left(q_{c}-q_{c l b}\right)
\end{aligned}
$$

The cloud ice content $q_{i}$ :

$$
\begin{aligned}
& \frac{\partial q_{i}}{\partial t}+\frac{1}{a \cos \varphi}\left[u \frac{\partial q_{i}}{\partial \lambda}+v \cos \varphi \frac{\partial q_{i}}{\partial \varphi}\right]+\eta^{*} \frac{\partial q_{i}}{\partial \eta}= \\
& F_{H}^{q_{i}}-g\left(\frac{\partial p}{\partial \eta}\right)^{-1} \frac{\partial \eta_{q_{i}}}{\partial \eta}+\left(\frac{\partial q_{i}}{\partial t}\right)_{s}-c_{v c}-\mu_{l b}\left(q_{i}-q_{i l b}\right)-\frac{\partial V_{f} \rho g q_{i}}{\partial \eta}
\end{aligned}
$$

where $V_{f}$ is the falling velocity of water rain and ice rain. The last equation (2.7) was added since the global model (GME) produces the $q_{i}$ variable (9/2003) to use as one more initial field for HRM. The HRM also computes 9 diagnostic variables with 9 equations. In the prediction products, there are also 4 indirect prognostic variables: the vertical velocity in the pressure coordinate, the geopotential height, the cloud cover factor and the diffusion parameter.

\subsection{Boundary conditions and initialization}

To filter the internal gravity wave developed in high resolution models, the HRM uses the radiation upper boundary condition (RUBC) after Klemp, Durran and Bougeaul (1983) [7]. The lateral boundary conditions are taken from the global model GME, so called derived model, with a smooth algorithm after Davies and Kalberg in order to enable gravity waves leaving the domain without a lot of reflections on the lateral boundaries. 
It is well known that we can't use directly observations as the initial condition. Observations have to be adjusted dynamically to form a set of appropriate analysis data for model initialization. The initialization procedure minimizes the growing of potential gravity waves as the model resolution becomes higher. In the HRM the implicit normal mode initialization method (INMI) is used, the results of which are the initialized fields $u, v, T$ and $p_{s}$. Since March 2005 instead of INMI we use the Digital Filter Initialization (DFI) developed by D. Majewski.

Model orography: For each of grid box, the average height above the sea level is updated from the American data set, depended on model resolution. The soil type in each box is taken from the FAO/UNESCO map.

\subsection{Physical process in HRM}

With the horizontal resolution from $28 \mathrm{~km}$ to $7 \mathrm{~km}$, models can't adequately represent the subgrid-scale processes such as radiation, convection, horizontal and vertical turbulence diffusion and the soil physical process directly and therefore must resort to parameterization in the HRM.

Radiation-the most important factor for the weather development is parameterized by two schemes separately for longwave and shortwave respectively in the atmosphere and at the surface (Doms and Schaettler 1977) [5]. HRM uses a prognostic scheme for parameterization microphysical processes of grid-scale clouds involved in rainfall generation. The scheme of Tiedtke (1989) [8] carried out for parameterization of deep convection, shallow convection and medium convection, while the horizontal turbulence diffusion is assumed as an unimportant physical process and is used like a filter to remove small scale noises. Vertical turbulence diffusion parameterization is based on the gradient flux approximation. Vertical diffusion parameters can be inferred from the diagnostic equation of turbulence kinematics $e_{T}$.

Soil model: The surface temperature and the surface evaporation rate aren't the HRM variables but they are necessary in the boundary condition for computing the radiation and heat flux. The soil humidity influences the water content in the planet boundary layer through its possible evaporation which affects rainfall or drought. The HRM uses the two-layer soil model of Jacobsen and Hesse (1982)[6], which estimates evaporation from bare soils and transpiration from vegetables using basic functions of water content followed a simplified version of Davis' parameterization scheme 1984.

\section{IMPROVED HRM AND ITS IMPLEMENTATION TO PREDICT TCS MOTION OVER THE SOUTH CHINA SEA}

\subsection{Improved HRM}

As we mentioned above, with the traditional forecasting methods using in Vietnam, we rarely predict the motion of slow-moving weak TCs unexpectedly changing the direction on coming into the South China Sea and hence predict erroneously theirs landfall. This is a serious problem in the operational forecasting in Vietnam. Numerical models of neighbor countries are unable to give anything better too. The typhoon Nepartak (0320) (2003) is a typical example. All of the centers predicted its landfall into the middle of Vietnam (about $18^{0} \mathrm{~N}$ ) on $17 / 11 / 2003$. In fact, coming near the shore typhoon Nepartak changed its direction drastically, went ahead to the North and fell into China. 
The operational implementing HRM with a horizontal resolution of $28 \mathrm{~km}, 20$ vertical levels for the large domain of $5^{0} \mathrm{~S}-35^{0} \mathrm{~N}, 80^{\circ} \mathrm{E}-130^{\circ} \mathrm{E}(\mathrm{V} 28-20 / \mathrm{L}$ ) proves that V28-20/L well predicts winter weather systems such as entries of cold air masses or the winter monsoon. Its forecast in summer is of a little lower quality but considerably useful for forecasters to improve their forecast reports.

The advantage of $\mathrm{V} 28-20 / \mathrm{L}$ with the large domain using time variable lateral boundary conditions provided by a global model is the ability capturing the impacting between large weather systems in the evolution of regional weather processes. Its main disadvantage is that the northwest boundary with the high mountains impacts on forecast qualities of the inside domain. Besides, TCs evolving over the model domain normally are weak and operating in a more limited region of the southwest Pacific. To understand the impact of boundary conditions on model results and to find out the appropriate domain for prediction of weak-storm motion over the South China Sea, we have chose a small domain of $7^{0} \mathrm{~N}-27^{0} \mathrm{~N}$ and $97^{0} \mathrm{E}-117^{0} \mathrm{E}$ with the same resolution as the V28-20/L which is called V28-20/S.

Disastrous weather phenomena in the tropical regions including TCs are mainly forced by tropical processes. The analysis of Carr and Elsberry (2000) [1] shows that as the TCs operates in inner tropical regions the errors in simulated positions are caused mainly by false simulation of meso-scale physical processes. Thus, to simulate tropical physical processes, we need to increase the resolution higher than that in the extra-tropical region. Besides, to simulate the motion of weak TCs over the South China Sea, it's necessary to detail the orography, which means a higher resolution. We have increased the horizontal resolution from $28 \mathrm{~km}$ to $14 \mathrm{~km}$ and with 31 vertical levels instciad of 20 levels of the old version for the same domain as the V28-20/S. This new version we call V14-31/S.

\subsection{Implementation of three versions to predict TCs motion over the South China Sea and results}

Three versions V28-20/L, V28-20/S and V14-31/S have been applied to predict motions of two typhoons Mekhala and Nepartak. The 2 days predicted errors of center position of typhoon Mekhala, started at $00 Z$ of 24, 25, 26/09/2002, and of typhoon Nepartak, started at $00 \mathrm{Z}$ on $16,17,18 / 11 / 2003$, by V28-20/L, V28-20/S and V14-31/S are given in the Table 1.

Our results (not represented here) show that analysis errors of TCs center (in column 2-distance between best track and analysis track of GME) are greater than that of 6 hours forecast. This means that the GME analysis fields are not good enough while the GMEHRM system shows a good appropriateness. The decrease of errors from analysis value (in column 2) to 6 hours predicted value (in column 3) implies that HRM is able to simulate well the evolution of typhoons operating over the South China Sea region.

The average errors (AE) of V14-31/S in Table 1 increase slowly and systematically with the forecast time (its $\mathrm{AE}$ are $69 \mathrm{~km}$ of one day forecast and $120 \mathrm{~km}$ of two days forecast) and in general considerable lower than errors of many other models. Taking the Australian TCLAPS model as an example for comparison, we see that the AE of TCLAPS are $143 \mathrm{~km}$ and $236 \mathrm{~km}$ respectively for 2001 year.

In the Figs. 1 and 2 we plotted tracks of above-cited typhoons, which is a line linked every 6 hours minimum surface pressure points estimated from forecast surface pressure field by the Downhill method. 
Table 1. Predicted center position errors $(\mathrm{km})$ of typhoons Mekhala and Nepartak by three versions: V28-20/L, V28-20/S \& V14-31/S

\begin{tabular}{|c|c|c|c|c|c|}
\hline Versions & $00 h$ & $12 h$ & $24 h$ & $36 h$ & $48 h$ \\
\hline Mekhala & & & & & \\
\hline V28-20/L & 61 & & 100 & & 181 \\
\hline V28-20/S & 55 & & 98 & & 140 \\
\hline V14-31/S & 85 & 69 & 87 & 135 & 127 \\
\hline Nepartak & & & & & \\
\hline V28-20/L & 116 & & 163 & & 285 \\
\hline V28-20/S & 104 & & 114 & & 90 \\
\hline V14-31/S & 116 & 39 & 51 & 65 & 112 \\
\hline Mean error & & & & & \\
\hline V28-20/L & 88 & & 132 & & 233 \\
\hline V28-20/S & 79 & & 106 & & 115 \\
\hline V14-31/S & 100 & 54 & 69 & 100 & 120 \\
\hline
\end{tabular}

PREDICTED TRACK OF WEKKHHLA STARTED OOZ-24/09/2002 EY HRH

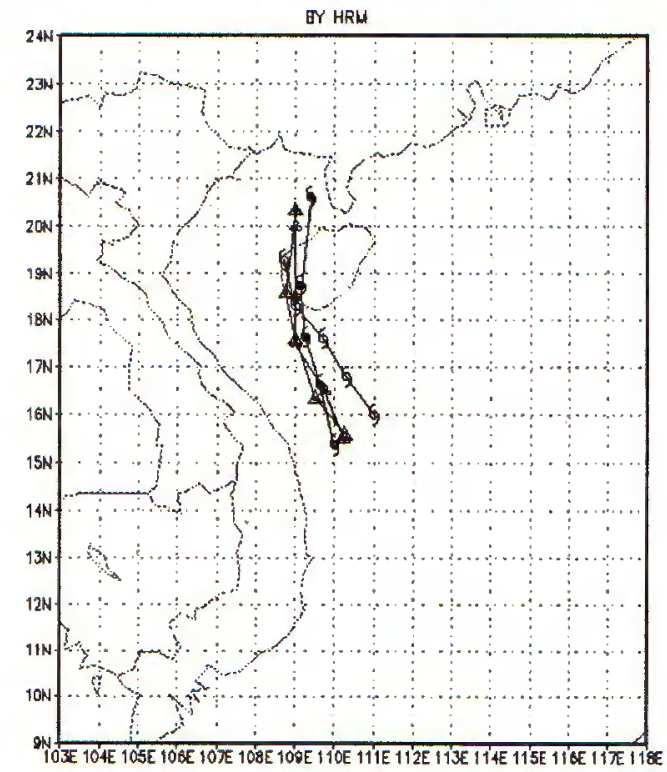

PREDICTED TRACK OF MEKKHAL STARTED ODZ-26/C9/2002 BY HRH

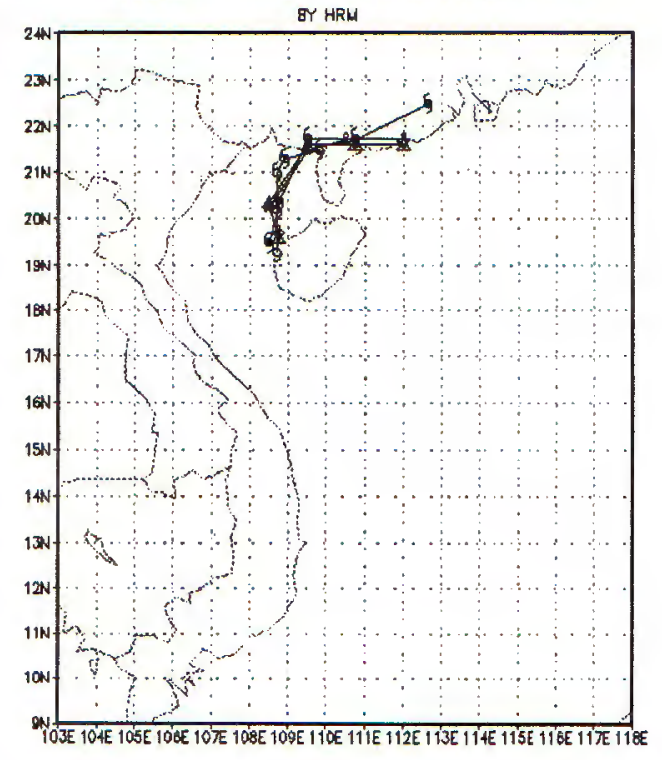

Fig. 1. Mekhala's predicted track, started at 00Z, 24092002 (top), at 00Z, 26092002 (bottom). 8: V28-20/L, : V28-20/S, 9 : V14-31/S, 9 : Best track.

Comparing predicted errors of V28-20/L with ones of V28-20/S we can deduce that reducing the forecast domain is an appropriate step that decreases predicted errors drastically and systematically, from $132 \mathrm{~km}$ to $106 \mathrm{~km}$ for first day forecast and from $233 \mathrm{~km}$ to $115 \mathrm{~km}$ for $2^{\text {nd }}$ days forecast. The 6 times reduce of integration time is a more important improvement because of economy on computer time. Predicted errors of V14-31/S show that 
with a higher resolution and an appropriate smaller domain, the forecast quality has been improved remarkably. The position errors are $69 \mathrm{~km}$ and $120 \mathrm{~km}$ for one day and two days forecast respectively. But the most significant improvement we can notice here is that V14-31/S shows a good capture of Nepartak's deflection started at 00Z-17/11/2003, its predicted track is the third line from the left- the most closed to the best track (Fig. 2), while the V28-20/L predicted the landfall of Nepartak into the Middle of Vietnam (about $18^{\circ} \mathrm{N}$ ) shortly before 00Z-19/11/2003 (the end of first line on the left in Fig. 2), and all forecast centers of neighbor countries gave nearly the same results.

The version V28-20/S has captured this deflection in the first day of forecast but took a turn to the north-west again in the second day of forecast (the second line from the left in Fig. 2) and hence its predicted errors are larger than those of V14-31/S respectively. So we can say that these results ensure the skill of improved version V14-31/S.

Figs. 3 to 12 depict 2 days forecasted tracks by V14-31/S of 10 storms (of 2002-2004) coming into the South China Sea and their corresponding best tracks. The results enable forecasters to increase systematically its forecast skill for TCs motion.

From all forecasted tracks represented in Figs. 3- 12 we can see that the TCs occurring in the first half of storm season in which the summer monsoon governs (such as Krovanh and Chanthu in June, Koni and Imbudo in July, Kammuri and Vongfong in August, Hagupit and Mekhala in September) normally deflect to the northeast of the analysis. On the contrary, the TCs occurring in the second half of storm season in which the winter monsoon governs (such as Nepartak and Muifa in November); deflect to the southwest of the analysis. Those results say that monsoon circulations affect strongly the velocity and direction of TCs motion over the South China Sea, and hence theirs landfall.
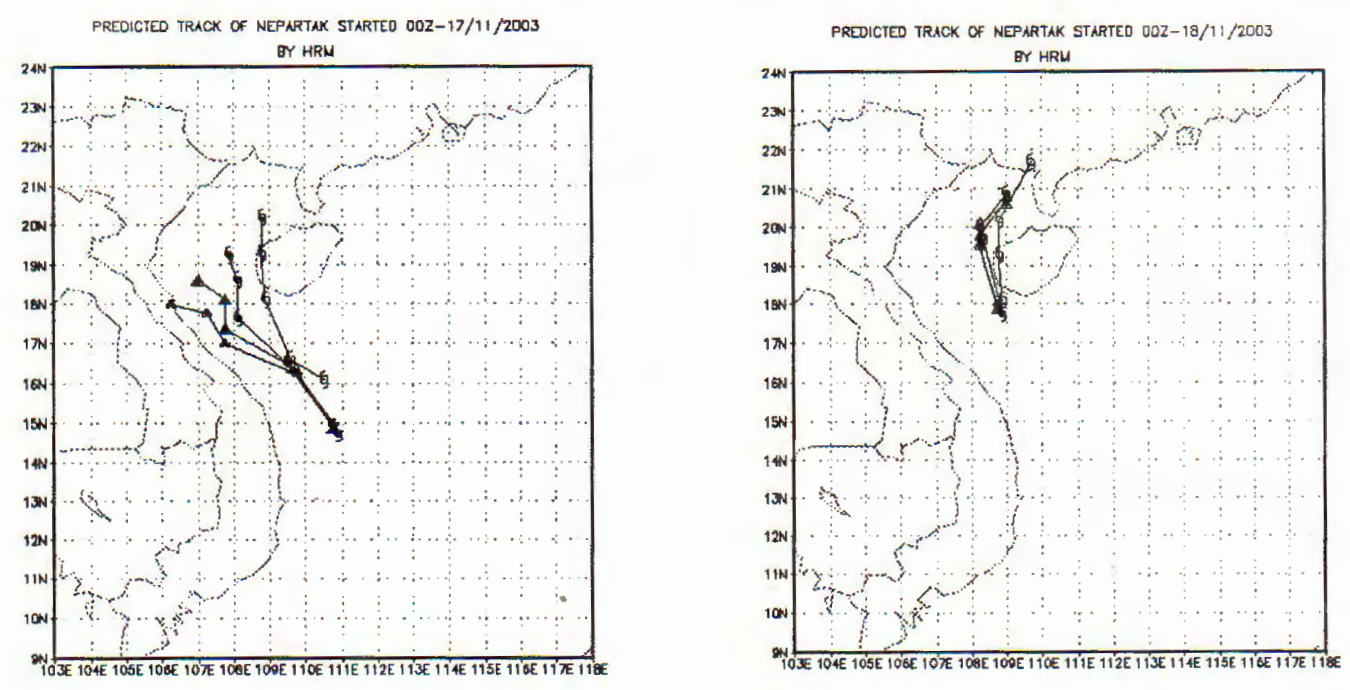

Fig. 2. Nepartak's predicted track, started at 00Z, 17112003 (left), at 00Z, 18112003 (right). s: V28-20/L, V28-20/S, $9:$ V14-31/S, 9 : Best track.

We have performed some verification of predicted motions using the V14-31/S by comparison with operational models from two countries. The results are given in the 
Table 2, where the errors of V14-31/S are averaged over 10 above-cited TCs. TCLAPS is an Australian coupled system between a global model and a limited regional model with a bogus artificial cyclone. KER is a moving nested model embedded in the global model T126 with an improving cyclone-set scheme using the optimal interpolation technique to define environmental fields in storm regions.

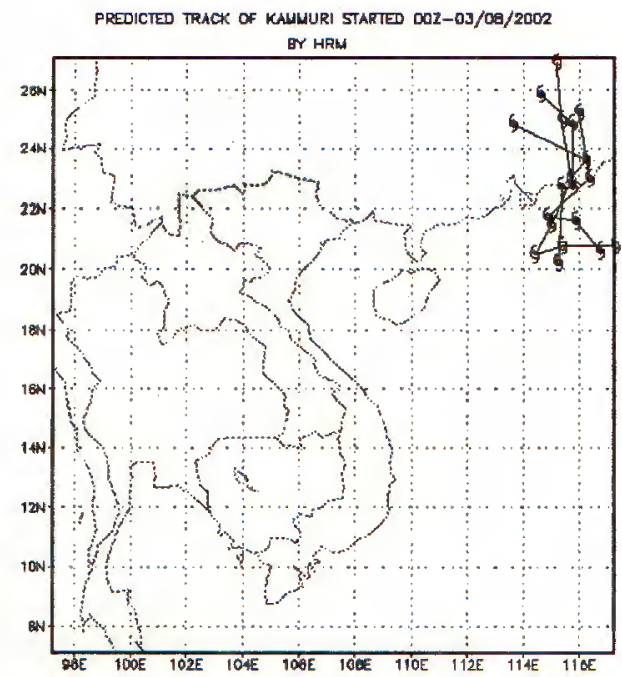

Fig.3. Kamuri's predicted tracks, started at $00 Z$ of $03,04 \& 05 / 08 / 2002$.

9. Best track.

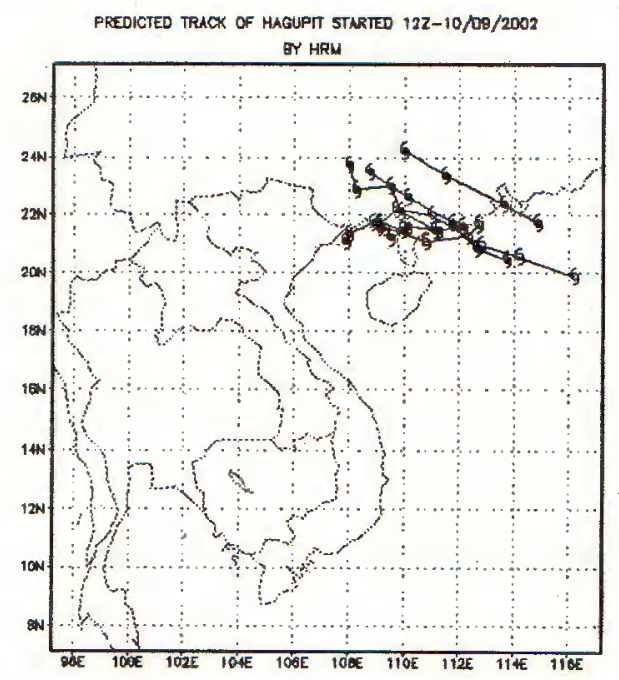

Fig. 5. Hagupit's predicted tracks, started at $00 \mathrm{Z}$ of $10,11,12,13 \& 14 / 09 / 2002$. 5: V14$31 / \mathrm{S}, 9$ : Best track.

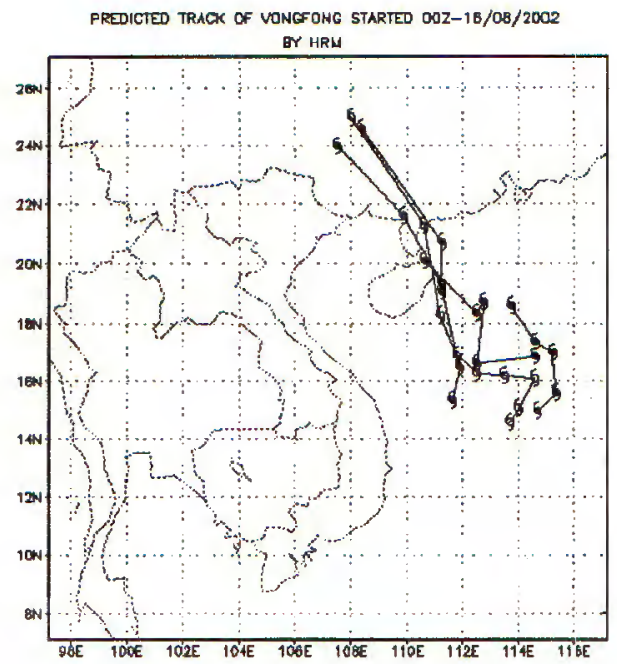

Fig. 4. Vongfong's predicted tracks, started at $00 \mathrm{Z}$ of $16,17,18 \& 19 / 08 / 2002$. 9 : V14$31 / \mathrm{S}, 9$ : Best track.

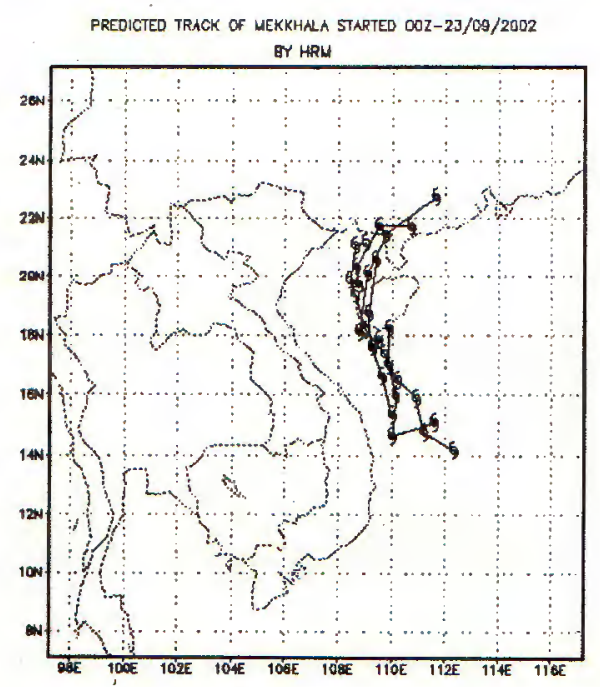

Fig.6. Mekhala's predicted tracks, started at $00 \mathrm{Z}$ of $23,24,25,26 \& 27 / 09 / 2002$. 5 : V14-31/S, 9 : Best track. 


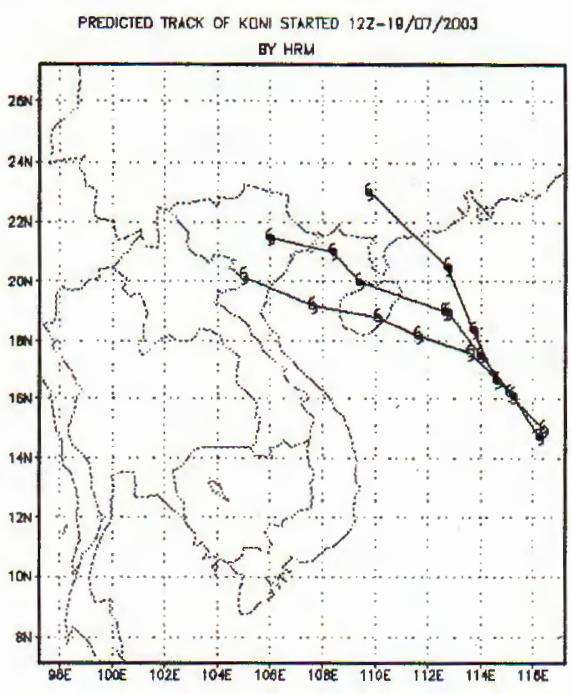

Fig. 7. Koni's predicted tracks, started at $00 \mathrm{Z}$ of $19,20 \& 21 / 07 / 2003.9: V 14-31 / \mathrm{S}, 9$ : Best track.

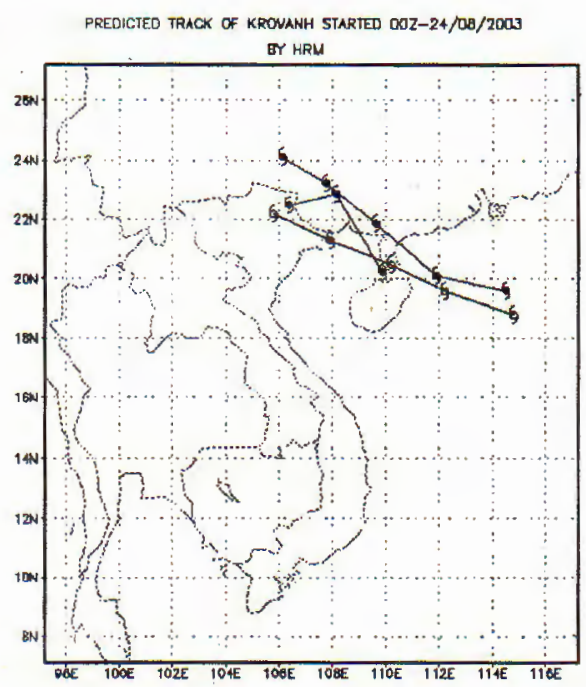

Fig. 9. Krovanh's predicted tracks, started at 00Z, 11-12/06/2003. 9: V14-31/S, 9: Best track,

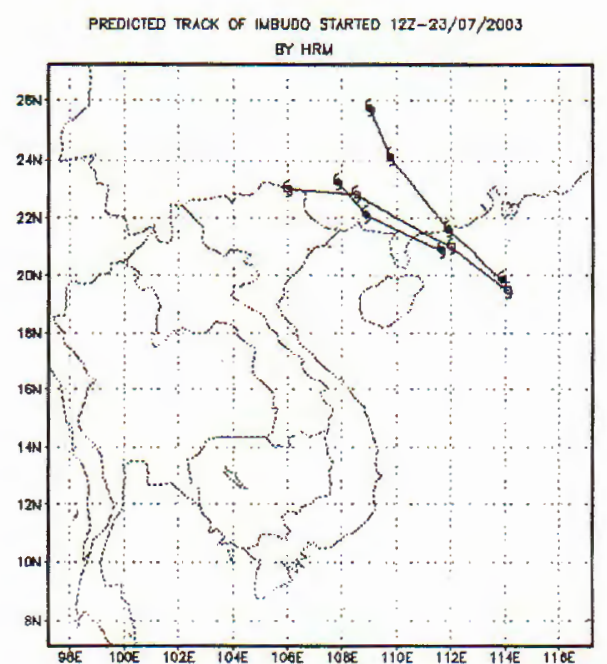

Fig. 8. Imbudo's predicted tracks, started at $00 \mathrm{Z}, 23-24 / 07 / 2003$. 5: V14-31/s, 9 : Best track.

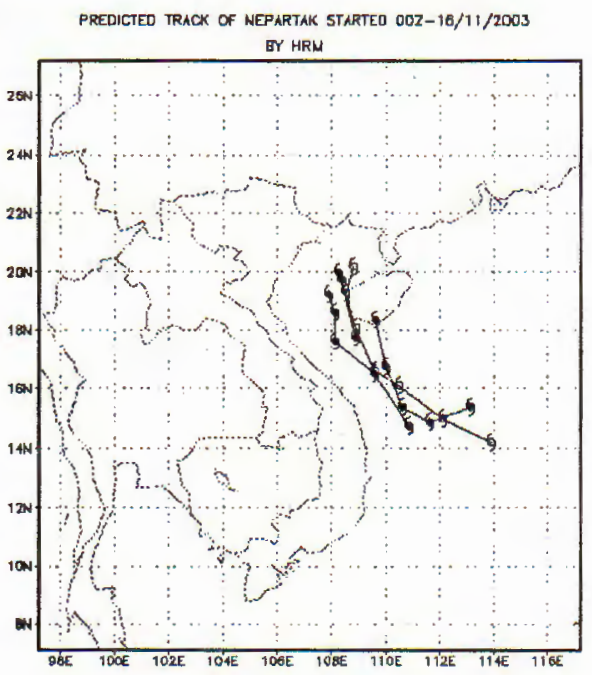

Fig. 10. Nepartak's predicted tracks, started at $00 \mathrm{Z}, 16,17 \& 18 / 11 / 2003.9: \mathrm{V} 14-31 / \mathrm{S}$, 9. Best track.

The results in Table 2 shows that predicted errors of V14-31/S in term 12 hours to 48 hours increase more slowly and are, systematically, lower than those one of TCLAPS and of KER. The remarkable thing is a too large analysis error for $\mathrm{V} 14-31 / \mathrm{S}$, which we can attribute for the quality of GME initial fields. However, after 12 hours integration, the 12hours error is less than the analysis error (103km in comparison to $119 \mathrm{~km}$ ). This means that V14-31/S simulated meso-scale and micro-physical processes in this tropical domain 
relative accurately, leading predicted fields more and more closely to the true fields during the first 12-hours integration. So if we can decrease analysis errors, the skill of V14-31/S would be better, which is one of the most important methods to increase the model skill.

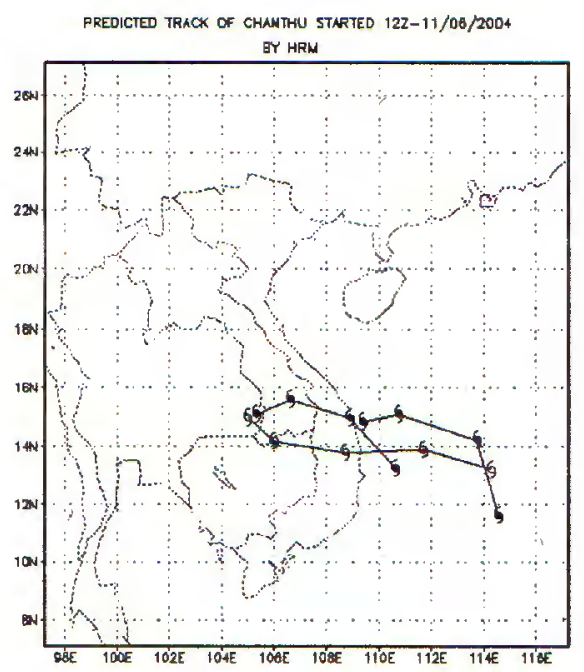

Fig. 11. Chanthu's predicted tracks, started at $00 \mathrm{Z}$ of 11 \& 12/06/2004. 9: V14-31/S, 9: Best track.

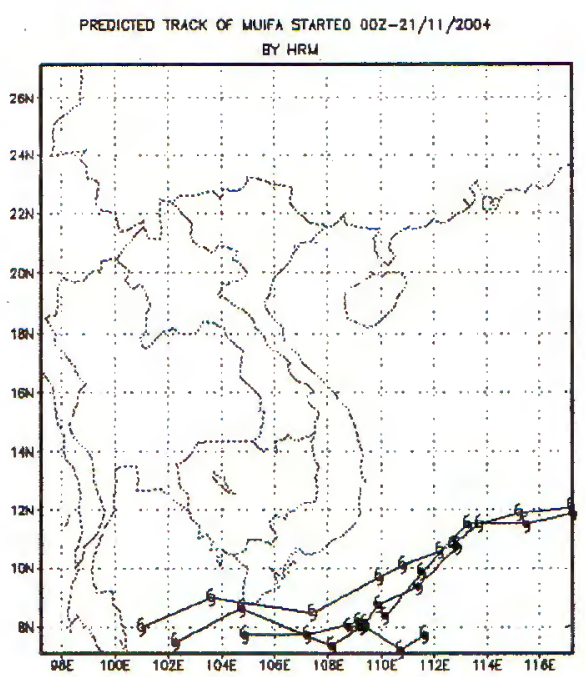

Fig. 12. Muifa's predicted tracks, started at $00 Z$ of $21,22,23 \& 24 / 11 / 2004$. 9: V1431/s, 9: Best track.

Table 2. TCs center position errors $(\mathrm{km})$, predicted by V14-31/S (2003-2004), TCLAPS (2001) and KER (1995).

\begin{tabular}{|c|c|c|c|c|c|}
\hline Model & $00 h$ & $12 h$ & $24 h$ & $36 h$ & $48 h$ \\
\hline TCLAPS & & 85 & 158 & 244 & 311 \\
\hline KER & & & 143 & & 236 \\
\hline V14-31/S & 119 & 103 & 132 & 148 & 218 \\
\hline
\end{tabular}

\section{CONCLUSION}

From the results we can deduce that the improved version by higher resolution combined with an appropriate domain V14-31/S is able to simulate relatively well tropical meso-scale and micro- physical processes so as without bogus cyclone setting V14-31/S can predict TCs motion and its landfall much better than other operational models of Australia and of USA. It's evident that the predicted skill of HRM will be improved when it is set bogus cyclones.

We have also predicted motions of typhoons Mekhala and Nepartak with the WBAR model and a 3-layers shallow water model (Kieu et all, 2002) [10]. Two those models have predicted Mekhala relative accurately but they did not capture the deflection of Nepartak. This demonstrate the advantage of hydro-dynamical models of high resolution in comparison with barotropic models because hydro-dynamical models of high resolution can describe tropical nonbarotropic processes as well as orographic changes in shore, which impact on the evolution and deflection of TCs. 
And we can assert the predicted skill of HRM for Vietnam and the South China Sea region. V14-31/S is running operationally at the Viet Nam National Hydro-Meteorological Service since 2002 October. Since then its results contribute considerably to the improvement of weather forecast quality in Viet Nam.

\section{REFERENCES}

1. L. E. Carr, R. L. Elsberry, Dynamical tropical cyclone track forecasting errors, Part I: Tropical region error sources, Wea. Forecasting 15 (2000) 641-661.

2. J. C. L. Chan, Prediction of annual tropical cyclone activity over the Western North Pacific and the South China Sea, International Journal of Climatology 15 (1995) 1011-1019.

3. C. P. Chang and T. C. George, Tropical circulations associated with southwest monsoon onset and westerly surges over the South China Sea, Mon. Wea. Rev. 123 (1995) 3254-3267.

4. R. E. Dickinson, Modeling evapo-transpiration for the three-dimensional global climate models, Climate processes and climate sensitivity 29 (1984) 58-72.

5. G. Doms, U. Schaettler, Eds, The nonhydrostatic limited area model LM. Part I: Scientific documentation, Deutscher Wetterdienst Rep. LM F90,1999.

6. I. Jacobsen and E. Heisse, A new economic method for the computation of the surface temperature in numerical models, Beitr.Phys. Atm. 55 (1982) 128-141.

7. J. B. Klemp and D. R. Durran, An upper boundary condition permitting internal gravity way radiation in numerical weather scale models, Month. Wea. Rev. 111 (1983) 430-444.

8. M. Tiedtke, A Comprehensive Mass flux scheme for cumulus parameterization in large scale models, Month. Wea. Rev. 117 (1989) 1799-1801.

9. C. T. Le and T. X. Kieu, A 3-layers shallow water model testing for prediction of storm trajectories over the South China Sea, Vie. Hyd. Met. Rev. 12 (516) (2003) 1-7.

10. T.X. Kieu et all, Research on application of high technological numerical models for prediction of storm movements over the South China Sea. Result Report of the 2000-2001 National Separate Scientific Technological Theme, 2002.

Received April 29, 2005

\section{MÔ HìNH DỰ BÁO THỜI TIẾT KHU VỰC PHÂN GIẢI CAO HRM VớI DỰ BÁO CHUYỂN ĐộNG CƯA XOÁY THỤ̂̂AN NHIỆT ĐỚI TRÊN BIỂN ĐÔNG}

Nghiên cứu cúa Chan (1995) đã chỉ ra rằng $70 \%$ trong 60 xoáy thuận nhiệt đới được nghiên cứu có chuyển động xác định bởi dòng dẫn. 30\% trường hợp còn lại cần được giải thích bằng các quá trình phi chính áp. Chúng tôi cho rằng các xoáy thuận nhiệt đới yếu, chuyển động chậm và đởi hướng đột ngột hoạt động trên biển Đông nằn trong 30\% trường hợp này. Tương tác phi tuyến giữa các quá trình chính áp và phi chính áp tác động đến chuyển động và cấu trúc của những xoáy thuận nhiệt đới loại này. Trong bài báo này chúng tôi sử dụng mô hình dự báo thời tiết phân giải cao (HRM) có thể mô phơng các hiện tượng thời tiết quy mô trung bình ở mức độ khu vực để dự báo chuyển động của xoáy thuận uhiệt đới trên biển Đông trong các năm 2002-2004, trong số đó có hai cơn bão yếu chuyển động chậm và thay đổi hướng đột ngột điển hình là Mekhala và Nepartak. Chúng tôi đã lựa chọn hai miền dự báo khác nhau về vị trí, diện và độ phân giải. Kết quả cho thấy với miền nhỏ có vùng đệm thích hợp và độ phân giải cao HRM có thể dự báo tốt hơn rõ rệt chuyển động của các xoáy thuận nhiệt đới này trên biển Đông. 